\title{
The time-dependent rearrangement of the epithelial basement membrane in human skin wounds - immunohistochemical localization of Collagen IV and VII
}

\author{
P.Betz ${ }^{1}$, A. Nerlich ${ }^{2}$, J.Wilske ${ }^{1}$, J. Tübel ${ }^{1}$, I. Wiest ${ }^{2}$, R.Penning ${ }^{1}$, and W. Eisenmenger ${ }^{1}$ \\ Departments of ${ }^{\mathbf{1}}$ Legal Medicine and ${ }^{2}$ Pathology, University of Munich, Frauenlobstrasse 7a, W-8000 München 2 , \\ Federal Republic of Germany
}

Received February 11, 1992 / Received in revised form March 23, 1992

Summary. In 62 human skin wounds (surgical wounds, stab wounds and lacerations after surgical treatment) we analyzed the immunohistochemical localization of collagen IV in the epithelial basement membrane. In 27 of these wounds the distribution of collagen VII, which represents a specific component of the basement membrane of stratified epithelia, was also analyzed. We were able to demonstrate a virtually identical co-distribution of both collagen IV and VII in the wound area with no significant time-dependent differences in the appearance of both collagen types. Fragments of the epithelial basement membrane could be detected in the wound area from as early as 4 days after wounding and after 8 days a complete restitution of the epithelial basement membrane was observed. In all cases with a wound age of more than 21 days the basement membrane was completely reformed over the former lesional area. The period between 8 and 21 days after wounding was characterized by a wide variability ranging from complete restitution to deposition of basement membrane fragments or total lack of the epidermal basement membrane.

Key words: Immunohistochemistry - Collagen IV and VII - Basement Membrane - Wound Age

Zusammenfasssung. Es wurden 62 menschliche Hautwunden (Operationsnähte, chirurgisch versorgte Stichund Riß-Quetsch-Wunden) untersucht. Neben Kollagen IV wurde in 27 Fällen zusätzlich Kollagen VII immunhistochemisch dargestellt. Es zeigte sich hierbei eine weitgehende Co-Verteilung von Kollagen IV und VII im Wundgebiet ohne daß relevante wundaltersabhängige Unterschiede bezüglich der Lokalisation im Bereich des Epithel-Defektes feststellbar waren. BasalmembranFragmente traten erstmals in 4 Tage alten Hautwunden

This study was supported by a grant from the "Deutsche Forschungsgemeinschaft" (grant Ei 209/3-1) as well as by a grant from the "Friedrich-Baur-Stiftung", University of Munich

Correspondence to: P. Betz auf. Frühestens 8 Tage nach Verletzung fanden wir eine komplette epidermale Basalmembran. Dies war in allen Präparaten mit einem Wundalter über 21 Tagen der Fall. Der Zeitraum zwischen dem 8. und 21. Tag nach Wundsetzung war charakterisiert durch eine erhebliche Variabilität der Befunde mit teils kompletter, teils fragmentiert vorliegender, teils auch noch vollständig fehlender Basalmembran im Defekt-Bereich.

Schlüsselwörter: Immunhistochemie - Kollagen IV Kollagen VII - Basalmembran - Wundalter

\section{Introduction}

Immunohistochemistry is not only useful for the detection of early changes during wound repair [3], but also provides significant information on the time-dependent appearance of various extracellular matrix components during the proliferative and reparative phases of wound healing.

In open skin wounds the closure of the wounded skin surface by reepithelialization starts from undamaged skin. Dividing basal cells of the epidermal layer proliferate to cover the lesional area. This migration is directed towards the wounded region [13]. Experimental studies have provided evidence that the migration of these epithelial cells is associated with the formation of a provisional matrix consisting of fibrin and fibronectin and that the basement membrane components laminin and collagen IV reappear when the fibrin and fibronectin in the wound area are organized [5].

The epidermal basement membrane is composed not only of laminin and collagen IV, but also contains collagen VII which is specific for the basement membrane. This unique collagen molecule forms the anchoring fibrils. Collagen VII has been localized exclusively in the basement membrane of the epidermis and other basement membranes of stratified epithelia [20].

The time-dependent rearrangement of the epithelial basement membrane component collagen IV in human 
P. Betz et al.: Collagen in skin wounds

skin wounds has up to now only been investigated by Eisenmenger and co-workers in cryostat sections using the immunofluorescence technique [7]. Investigations concerning the time-dependent appearance of collagen VII in human wound healing have not yet been carried out.

In the present study the basement membrane components collagen IV and VII were visualized in paraffin sections by immunohistochemistry to provide further information on the time-dependent rearrangement of the epithelial basement membrane during human wound healing.

\section{Material and methods}

A total of 62 human skin wounds (surgical wounds, stab wounds and lacerations after surgical treatment) with a wound age ranging from 1 day to 6 weeks were investigated. The specimens were obtained at autopsy from individuals aged between 15 and 92 years (average 54 years). The postmortem interval did not exceed 3 days.

From each skin wound at least 2 specimens were taken and fixed in 4\% PBS-formaldehyde solution and then embedded in paraffin. Sections (thickness $2-3 \mu \mathrm{m}$ ) were prepared and after enzymatical pretreatment to enhance immunoreactivity [2], stained with a polyclonal antibody to collagen IV (LaboServ, Giessen, FRG) in combination with the ABC-method [8]. In 27 of the specimens serial sections were additionally stained with a monoclonal antibody against collagen VII (kindly supplied by Dr. R. Burgeson, Portland, Oregon, USA) using the APAAP-technique [6]. Undamaged skin as well as sections without the inclusion of the primary antibody were used as controls.

\section{Results}

\section{Normal skin}

Collagen $I V$. In normal skin the epithelial basement membrane of the epidermal layer and the basement membrane of skin appendages and blood vessels showed a strong positive reaction. The sheath of nerve and muscle cells and the basal lamina surrounding adipocytes also stained positively.

Collagen VII. Positive reactions were restricted strictly to the epithelial basement membrane of the epidermis and of skin appendages. In contrast to collagen IV no positive reaction was found in the basement membrane of blood vessels, adipocytes, nerve or muscle cells.

The specimens stained without inclusion of the primary antibody gave no positive reactions.

\section{Skin wounds}

Collagen $I V$. Fragments of the epithelial basement membrane were detectable as early as 4 days after wounding. Complete rearrangement of the basement membrane did not occur before the 8th day after wounding and could be observed in all cases with a wound age of more than 21 days. Out of 24 lesions aged between 8 and 21 days $7(29 \%)$ showed also a complete basement membrane covering the former wound area and in 13 cases
$(54 \%)$ fragments of the basement membrane were detectable. The remaining 4 cases $(17 \%)$ showed a complete lack of positive staining demonstrating total absence of the epithelial basement membrane in the wound area. These cases had a wound age between 11 and 13 days.

Significant differences in the restitution of the basement membrane dependent on the age of the individuals or on the wound localization could not be found.

Collagen VII. Out of the 27 specimens which had been stained for both collagen IV and collagen VII, the wound area in 19 cases showed a virtually identical staining pattern for both antibodies providing evidence of a codistribution of collagen IV and VII in the lesional area (Figs. 1 and 2). No significant time-dependent differences were detectable.

\section{Discussion}

Basement membranes separate epithelial, muscle, and nerve cells as well as adipocytes from the surrounding connective tissue. They are defined as structures possessing a lamina densa and a lamina rara [12]. Beneath the lamina densa there exists an anchoring region, the lamina fibroreticularis, with multiple fibrils forming the contact to the underlying connective tissue and leading to a regular 3-layer structure of basement membranes [18].

Laminin, collagen IV, a basement membrane-specific heparan sulfate proteoglycan and entactin are obligate components of all basement membranes and are therefore called "intrinsic components". Besides these "intrinsic components" basement membranes often contain other extracellular matrix proteins such as fibronectin and type $\mathrm{V}$ collagen, which are called extrinsic components [12]. Other authors differentiate between collagenous (type IV and VII collagen) and non-collagenous (proteoglycans, laminin, entactin, nidogen, fibronectin, amyloid $\mathbf{P}$ ) components [1] .

Type IV collagen is an ubiquitous basement membrane component and consists of 3 (different) alpha (IV) chains which are arranged in the form of a triple helix containing also globular domains $[10,14,18]$. Crosslinking of multiple collagen IV molecules leads to the formation of a network-like structure of covalent-binding collagen IV which is responsible for the mechanical stability of the basement membrane [17].

In contrast to collagen IV, type VII collagen in normal skin is restricted to the epithelial basement membrane of the epidermal layer and the skin appendages only [20]. Collagen VII was first called "long chain collagen" and occurs mainly as an antiparallel dimer with overlapping ends [4]. Collagen VII is the major component of the anchoring fibrils in the lamina fibroreticularis of the basement membrane $[11,16]$. Anchoring fibrils are specialized structures mediating close contact between the lamina densa and the underlying connective tissue. The carboxylterminal domain of collagen VII is inserted in the collagen IV containing "anchoring 


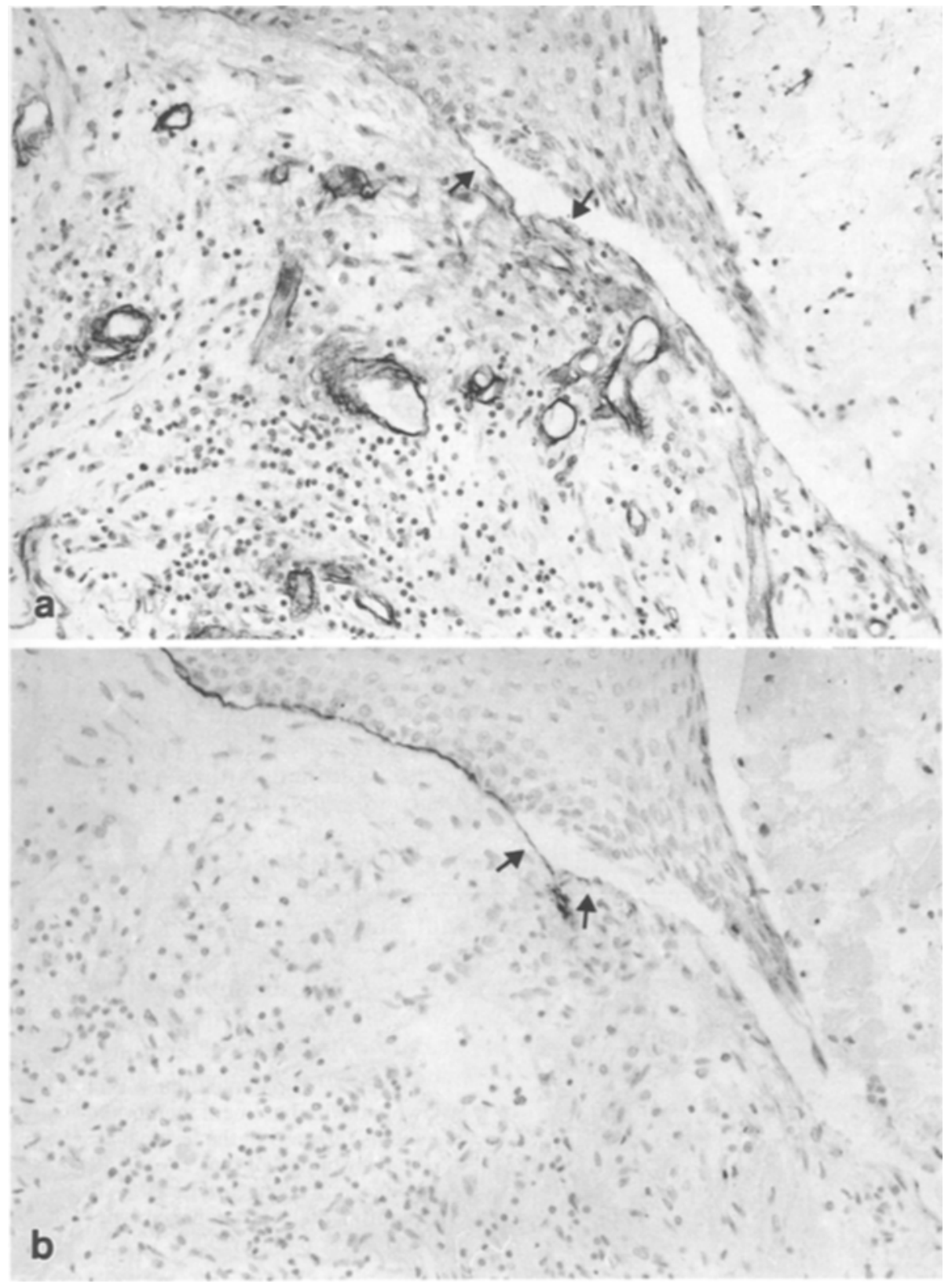

Fig. 1a, b. 14-day-old human skin wound showing basement membrane fragments (arrows) in the wound area; co-distribution of type IV and VII collagen. a immunohistochemical localization of collagen type IV (ABC, paraffin, $300 \times$ ). b immunohistochemical localization of collagen type VII (APAAP, paraffin, $300 \times$ ) plaques" lying beneath the lamina densa. The anchoring fibrils extend into the papillary dermis connecting the epidermal layer to the connective tissue fibers [9].

Basement membranes play a vital role in various biological processes. They represent an extracellular network responsible for mechanical stability and form a barrier to the passage of macromolecules from blood. They are involved in the morphological differentiation of tissues [1]. It is also discussed that differentiating cells utilize basement membranes as migratory substrates [19]. However, Clark and co-workers [5], showed that the migration of epithelial cells during wound healing is associated with the formation of a provisional matrix consisting of fibrin and fibronectin while the basement membrane components laminin and collagen IV are lacking at this point in time. They reappeared 7-9 days after wounding when fibrin and fibronectin disappeared in the lesion area in standardized skin wounds $(4 \mathrm{~mm}$ punch biopsies) of guinea pigs.

Studies on the time-dependent reappearance of the basement membrane component collagen IV in human skin lesions have previously only been carried out by Eisenmenger et al. [7]. The appearance of collagen VII in this context has not yet been investigated.

Eisenmenger and co-workers [7] reported a reappearance of basement membrane fragments in the wound area as early as the 5 th day after wounding. A complete restitution occurred first in a 9-day-old skin lesion and could always be observed in skin wounds with a wound age of 14 days or more. Between the 9th and 14th day after wounding wide variations concerning the rearrangement of the epithelial basement membrane could be 




Fig. 2a, b. 17-day-old human skin wound with basement membrane fragments (arrows) in the lesional area; co-distribution of type IV and VII collagen. a collagen type IV (ABC, paraffin, $300 \times$ ). b collagen type VII (APAAP, paraffin, $300 \times$ ) found. A complete restitution, as well as the presence of basement membrane fragments or even a total lack of the basement membrane, have been observed.

Similar to the results of Eisenmenger et al. [7] we have found that the first fragments of the basement membrane appeared in the lesional area of a skin wound after 4 days. A complete restitution of the basement membrane of the epidermal layer was not seen before the 8th day after wounding and was present in all cases with a wound age of more than 21 days, i.e. approximately one week later than reported by Eisenmenger et al.. This difference may be explained by the smaller number of samples evaluated by this group.

Any influence of the wound area on the results can be excluded, as only surgical wounds were evaluated in both studies. The period between 8 days and 21 days after wounding was characterized by the same variability as described by Eisenmenger and co-workers for wound ages ranging from 9 to 14 days. In $29 \%$ of the cases a completely restituted basement membrane was present in the former wound area and in 54\% fragments of the basement membrane were detectable. The remaining $17 \%$ were characterized by a total lack of the basement membrane in the lesional area, but these wounds were not older than 13 days. The differences concerning the reappearance of the basement membrane in our series compared to the experimental results of Clark et al. [5] could be due to the methodology. It can be assumed that biological processes, especially wound healing, proceed somewhat faster in small animals than in man and therefore the results obtained from experimental animals cannot simply be transferred to humans. Secondly the type of wounding in this experimental analysis was different than in our series. Clark et al. [5] took $4 \mathrm{~mm}$ punch bi- 
opsies from the skin of guinea pigs and this wound type is different from the surgically treated lesions evaluated in this study and by Eisenmenger and co-workers [7].

These factors could also explain the differences between our results and the findings of Rigal et al. [15] concerning the time-dependent reappearance of collagen IV and collagen VII. These authors evaluated unsutured skin wounds in pigs from day 1 to day 20 after wounding and found that collagen VII was detectable as early as the 3 rd day after wounding. Collagen IV, however, was already present in the lesional area after the 1st day.

In summary, our results provide the following information for the time estimation of surgical human skin wounds by the immunohistochemical detection of collagen IV and VII:

Fragments of the basement membrane are initially detectable 4 days after wounding. It can be assumed, that in skin wounds with a wound age of more than 13 days, these fragments are always present.

A complete rearrangement of the epithelial basement membrane can be found in skin wounds with a wound age of 8 days or more. At about 21 days or more a complete basement membrane can be expected in all cases.

Collagen IV and collagen VII are co-distributed in the wound area in human skin lesions with no significant differences in the location or the time-dependent reappearance of these collagen types.

The immunohistochemical detection of the basement membrane components collagen IV and VII for the time-estimation of skin wounds thus provides identical results. These values, however, are only relevant for surgically treated wounds.

Significant differences in these wound healing properties do not seem to depend on the age of the individuals or on the localization of the wounds.

\section{References}

1. Abrahamson DR (1986) Recent studies on the structure and pathology of basement membranes. J Pathol 149:257-278

2. Barsky SH, Rao NC, Restrepo C, Liotta LA (1984) Immunocytochemical enhancement of basement membrane antigens by pepsin: applications in diagnostic pathology. Am J Clin Pathol 82:191-194

3. Betz P, Nerlich A, Wilske J, Tübel J, Wiest I, Penning R, Eisenmenger W (1992) Immunohistochemical localization of fibronectin as a tool for the age determination of human skin wounds. Int J Leg Med 105:21-26

4. Burgeson RE, Morris NP, Murray LW, Duncan KG, Keene DR, Sakai LY (1986) The structure of type VII collagen. Ann NY Acad Sci 460:47-57
5. Clark RAF, Lanigan JM, DellaPelle P, Manseau E, Dvorak HF, Colvin RB (1982) Fibronectin and fibrin provide a provisional matrix for epidermal cell migration during wound reepithelialization. J Invest Dermatol 79:264-269

6. Cordell JL, Falini B, Erber WN, Ghosh AK, Abdulaziz Z, MacDonald S, Pulford AF, Stein H, Mason DY (1984) Immunoenzymatic labeling of monoclonal antibodies using immune complexes of alkaline phosphatase and monoclonal antialkaline phosphatase (APAAP-complex). J Histochem Cytochem 32:219-229

7. Eisenmenger W, Nerlich A, Glück G (1988) Die Bedeutung des Kollagens bei der Wundaltersbestimmung. Z Rechtsmed 100:79-100

8. Hsu SM, Raine L, Fanger H (1981) A comparative study of the peroxidase-antiperoxidase method and an avidin-biotin complex method for studying polypeptide hormones with radioimmunoassay antibodies. Am J Clin Pathol 75:734-739

9. Keene DR, Sakai LY, Lunstrum GP, Morris NP, Burgeson RE (1987) Type VII collagen forms and extended network of anchoring fibrils. J Cell Biol 104:611-621

10. Kefalides NA, Alper R, Clark CC (1979) Biochemistry and metabolism of basement membranes. Int Rev Cytol 61:167228

11. Lunstrum GP, Sakai LY, Keene DR, Morris NP, Burgeson RE (1986) Large complex globular domains of type VII procollagen contribute to the structure of anchoring fibrils. J Biol Chem 261:9042-9048

12. Martinez-Hernandez A, Amenta PS (1983) The basement membrane in pathology. Lab Invest 48:656-677

13. Oehlert W, Büchner T (1961) Mechanismus und zeitlicher Ablauf der physiologischen Regeneration am mehrschichtigen Plattenepithel und in der Schleimhaut des Magen-DarmTraktes der weißen Maus. Beitr Pathol Anat 125:373-402

14. Piez KA (1987) Collagen types: a review. In: Sen A, Thornhill $T$ (eds) Development and diseases of cartilage and bone matrix. Orthopedic Division UCLA Symposion; Alan R.Liss, New York, pp 1-19

15. Rigal C, Pieraggi M-T, Vincent C, Prost C, Bouissou H, Serre G (1991) Healing of full-thickness cutaneous wounds in the pig. I. Immunohistochemical study of epidermo-dermal junction regeneration. J Invest Dermatol 96:777-785

16. Sakai LY, Keene DR, Morris NP, Burgeson RE (1986) Type VII collagen is a major structural component of anchoring fibrils. J Cell Biol 103: 1577-1586

17. Timpl R, Wiedemann H, Van Delden V, Furthmayr H, Kühn K (1981) A network model for the organization of type IV collagen molecules in basement membranes. Eur J Biochem 120: 203-211

18. Timpl R, Dziadek M (1986) Structure, development, and molecular pathology of basement membranes. Int Rev Exp Pathol $29: 1-112$

19. Vracko R (1974) Basal lamina scaffold - anatomy and significance for maintenance of orderly tissue structure. Am J Pathol $77: 314-346$

20. Wetzels RHW, Robben HCM, Leigh IM, Schaafsma HE, Vooijs GP, Ramaekers FCS (1991) Distribution patterns of type VII collagen in normal and malignant human tissues. Am J Pathol 139:451-459 